\title{
STS, Post-truth, and the Rediscovery of Bullshit
}

\author{
BENNETT HOLMAN \\ YONSEI UNIVERSITY \& UNIVERSITY OF JOHANNESBURG
}

\begin{abstract}
Post-truth politics has led to a number of prominent reflections on the extent to which the basic tenets of STS (social construction, the symmetry thesis, etc.) must be amended (Briggle 2016; Latour 2004; Sismondo 2017a). Alternatively, others have argued that the basic principles of STS should be maintained and the similarities of STS with post-truth should be embraced (Fuller 2016b; Woolgar 2017). After first critiquing other scholars read on post-truth politics, I argue that one of the central drawbacks of STS is the absence of epistemic grounds to identify people who are plainly bullshitters (Frankfurt 1986). I contend that the lesson that post-truth politics has to offer STS is that a minimal standard of an epistemological system is that it must have the intellectual resources to endorse the claim "Trump is full of shit." Yet it is not clear how one could go about reconciling central STS tenets with the clear and present need to oppose dangerous trends in contemporary politics. Despite arguing that STS should change, I contend that it should not do so at the expense of what is distinctive and valuable about STS. After considering Steve Woolgar's (2017) list of the strengths of STS scholarship I propose that with slight modification they can be preserved. As an example of an epistemology which does so, I introduce Helen Longino's critical contextual empiricism and then use it to analyze a case study of the recent FDA approval of flibanserin for hypoactive sexual desire disorder. I conclude by arguing that social epistemology, as developed in philosophy of science, is reconcilable with opposing post-truth politics and retains many of the primary virtues of STS.
\end{abstract}

\section{Keywords}

post-truth; social epistemology; symmetry thesis 


\section{Introduction}

There is a crisis of sorts amongst the STS community. It seems, to some at least, that the postmodern critique has fallen into the wrong hands. Pandora's Box has been opened; the deconstructed chickens have come home to roost. This has led to a number of prominent reflections on the extent to which the basic tenets of STS (social construction, the symmetry thesis, etc.) must be amended (Briggle 2016; Latour 2004; Sismondo 2017) or can continue to be embraced (Fuller 2016b; Woolgar 2017).

After first reviewing and critiquing recent reflections, I argue that the central feature of post-truth politics is the erosion of transpolitical institutions' authority to regulate political discourse. 2 The result of this is the proliferation of what Harry Frankfurt (1986) delicately terms "bullshit." The quintessential feature of bullshit can best be seen by distinguishing it from its close cousin, the lie.

Unlike plain lying, however, it is more especially a matter not of falsity but of fakery. This is what accounts for its nearness to bullshit. For the essence of bullshit is not that it is false but that it is phony. In order to appreciate this distinction, one must recognize that a fake or a phony need not be in any respect (apart from authenticity itself) inferior to the real thing. What is not genuine need not also be defective in some other way. It may be, after all, an exact copy. What is wrong with a counterfeit is not what it is like, but how it was made. This points to a similar and fundamental aspect of the essential nature of bullshit: although it is produced without concern with the truth, it need not be false. The bullshitter is faking things. But this does not mean that he necessarily gets them wrong. (p.12)

Both the liar and bullshit artist misrepresent a state of affairs, but the character of the misrepresentation is distinct. The liar must have a keen appreciation of truth in order to weave their lie seamlessly into it and hide the truth the lie covers over. The bullshit artist hides the fact that the truth values of their claims are of little interest to him. As a result, he "has much more freedom. His focus is panoramic rather than particular. He does not limit himself to inserting a certain falsehood at a specific point, and thus he is not constrained by the truths surrounding that point or intersecting it. He is prepared to fake the context as well, so far as need requires" (p.13). In line with Frankfurt's conceptual distinctions, I suggest that what is profoundly disturbing about politicians like Donald Trump is not that he says untrue things, it is that he does not care whether the things he says are true.

But if this is the correct understanding of post-truth, it presents STS scholars with a dilemma. They may well feel sympathy with Frankfurt's ideas as they apply to post-truth, but have little interest in endorsing the analytic philosophy out of which it arises. With that, I would agree, I think that there is much about STS worth saving.

\footnotetext{
2By "transpolitical institution," I mean to pick out those formal or informal organizations that are acknowledged by both parties as adjudicating political debates and/or establishing a shared body of fact (e.g., the Congressional Budget Office is generally accepted by all parties as an authoritative source on the expected costs of proposed legislation).
} 
Of course, one could save it all and endorse post-truth politics (e.g. Fuller). On the other hand, it might be worth considering what one would have to give up to gain an intellectual foundation sufficient for critique. As a test of sufficiency, I suggest that any acceptable epistemological system must be strong enough to distinguish and exclude bullshit. After arguing that STS currently lacks the theoretical resources to critique post-truth politics, I consider Steve Woolgar's (2017) list of its strengths and argue that with slight modification they can be preserved. Inext introduce one such account and then use it to analyze a case study of the recent FDA approval of flibanserin for hypoactive sexual desire disorder. I conclude by arguing that the epistemological framework is reconcilable with opposing post-truth politics and retains many of the primary virtues of STS.

\section{Out of Steam}

This moment of crisis is unquestionably prompted by repeated shocks to the expectations of the political left, most notably Brexit and then the election of Donald Trump, but no less importantly by the rise of fascist parties across Europe more generally. For the sake of simplicity, I will focus on the American context, but this is not to imply that those living outside the US (and Europe), as I am, are not affected as well. The whole world is affected by what is done on issues such as global warming, but there are several issues of resource depletion (e.g. phosphorous) and environmental degradation (e.g. mass extinction) that impact the global community, but which will be decided by the centers of geopolitical power.

Yet what is most threatening to many is not an opposition to pressing global problems, but the way in which post-truth politics erodes the very core of the enlightenment: the idea that critical thinking, open debate, and evidence will promote human flourishing and good governance. Perhaps such concerns seem quaint and Pollyannaish to those who long ago learned to distrust and deconstruct grand narratives. However, I take it that what is most threatening to the STS community is that they see parallels with the rhetorical and intellectual tools they have honed professionally and those now being used to support political causes they oppose.

One clear way out of this dilemma is to accept that there is no sound ground for opposition (Fuller 2016b). One thing Fuller is surely right about is that the Oxford English dictionary definition of "post-truth" mischaracterizes the situation as: "Relating to or denoting circumstances in which objective facts are less influential in shaping public opinion than appeals to emotion and personal belief." The OED definition is what Fuller (2016a) calls "the lion's truth"; it is a way for those whose power is eroding to attempt to discredit the epistemic insurgents. As Fuller suggests, this would be an era of epistemological democratization, where the means of (knowledge) production, and he should say critique, are made accessible to the masses. Either there are normative grounds to say that these insurgents are illegitimate, or we must accept that the "experts" have no claim to deference.

Presumably the crisis in STS is the reluctance to follow critique to its logical end. Such concerns were prefigured by Bruno Latour's (2004) reflections on the science wars. Faced with a near scientific consensus in the reality of anthropogenic climate change, Latour reflects on the 
leaked memo of a Republican political strategist who recommends emphasizing the lack of scientific certainty: "the scientific debate is closing in around us... should the public come to believe that the scientific issues are settled, their views about global warming will change accordingly" (Luntz, as quoted by Editorial (New York Times), as quoted by Latour 2004, p. 226)). Though Latour has spent his career in exposing the uncertainty behind closed debates, here he worries that the threat to society has shifted such that "the danger would no longer be coming from an excessive confidence in ideological arguments posturing as matters of fact... but from an excessive distrust of good matters of fact disguised as bad ideological biases (p. 227)!"

On what grounds can STS scholars endorse this claim? One ground would be if Luntz was self-consciously recommending that, given that the facts do not support Republican objectives, politicians must obscure them. In short, Republicans must keep people ignorant of the truth lest the public be convinced by reasoned arguments and well-established scientific facts. In this scenario, scholars are not disputing anything Luntz says, they are merely revealing what is going on behind the curtain. However, while this is the typical portrayal of Luntz's leaked memo in the agnotology literature (e.g. Michaels 2008; Mirowski 2013; Fernandez Pinto 2017), a full reading of the memo shows Luntz's position is nearly the opposite.

In Luntz's (2002) telling, it is the political left that have been inducing the public to act irrationally. In summary, Luntz argues that Democrats have convinced the public that Republicans:

are in the pockets of corporate fat cats... [and are] cold, uncaring, ruthless, even downright anti-social. These attacks appeal to resentment and fear. Because they are primarily emotional in nature, they cannot be blunted with logic or statistics. Therefore, any discussion of the environment has to be grounded in an effort to reassure a skeptical public that you care about the environment for its own sake. (p. 132)

Luntz is not recommending that Republicans lie; rather he is arguing that even though Republicans have better supported arguments that are more in line with the political will of the general population, they are failing to gain public support because of Republican's stubborn adherence to fact-based, logical argumentation. Luntz's actual message is not that "the facts don't matter" but that "facts only become relevant when the public is receptive and willing to listen to them" (p. 133). He argues that environmental regulation would impose known costs on the economy (many of which would disproportionately affect the poor and elderly) and that given the uncertainty (circa 2002) about climate change, regulations like the Kyoto protocol should be resisted. As long as there is residual uncertainty and the public knows it, the public will oppose costly regulation.

Rather than a guide on how to benight the public, the rhetoric of the Luntz memo is a guide to combating "democratic demagoguery" so that rational argumentation and fact-based reasoning can prevail. The norms of expertise and evidence giving are often still in effect within a circumscribed boundary of who counts as an expert. Luntz may in fact be promoting ignorance, but that is not his explicit argument. Thus, if Luntz is to be retained as a paradigm case of agnotology, it requires some normative grounds for staking out when debate is reasonable. 
Without a similar standard in politics, the OED definition of the post-truth era as "one in which emotion and personal belief have supplanted truth and objective facts as arbiters of discourse" is, as Fuller says, merely the lion's truth. It is the description of post-truth politics from the perspective of the past and it presupposes that one already has a hold on which claims are objectively true facts and which are merely conveniently conjured figments of a political agenda. It presupposes something along the lines of the following: "We live in two universes. One universe is a lie... The institutions that are run, dominated, and controlled by this new brand of post-truth politician both in the US and around the world are detached from the truth. The other universe is where we are, and that's where reality reigns supreme and we deal with it. And seldom do these two universes ever overlap." This is not how the political right understands their own discourse. Or rather, this is exactly how the right understands their own discourse, the only difference is that the right disagrees about which universe is in touch with reality. To put a point on it, the description above is taken nearly verbatim from Rush Limbaugh (2009) — for his sentiments simply replace "this new brand of post-truth politician" with "the political left."

Without a standard, we are left with both sides claiming to have unmasked the irrationality and deceit of the other. In later sections, I will outline an account that possesses a normative bite capable of distinguishing between legitimate and illegitimate dissent and use it adjudicate a dispute about the use of drugs to treat female sexual dysfunction. Yet, before I do so, I want to address objections that the similarities between post-truth and STS are superficial. Addressing such objections substantiates the claim that the rise of post-truth politics rightly caused a crisis in STS.

\section{Through the Airwaves Darkly}

The central claim of this paper is that the key sensibilities of STS are insufficient to critique posttruth politics and so stand in need of modification. Several scholars have rejected this claim (e.g., Hoffman 2018; Sismondo 2017b); thus, before I proceed I will locate my understanding of posttruth politics in the history of conservative media critique in order to sharpen my disagreement with those who think it to be radically distinct.

If one harkens back to the yellow journalism of the nineteenth century, it is not entirely clear that post-truth politics is new. As Jonathan Ladd details, "the existence of an independent, powerful, widely respected news media establishment is an historical anomaly" (2011, p. 6). Nevertheless, with the establishment of the Columbia School for Journalism and owners like Aldolph Ochs at the helm of the New York Times, by the mid-twentieth century, journalism had been professionalized and adopted a set of norms that extolled the ideals of "objectivity"operationalized as accurate, fact-based, even-handed, and impartial reporting.

\footnotetext{
${ }^{3}$ I am indebted to David Roberts (2017) for bring the "two universes" quote to my attention. He argues that the rejection of transpolitical institutions has led to what he calls "tribal epistemology," where what is good for my side becomes equated with the truth. While I agree with his claims regarding the erosion of the authority of transpolitical institutions, I disagree with his characterization of tribalized epistemology insofar as within each party there remain standards of argumentation, deference to (the right kind of) experts, etc.
} 
As detailed by Nicole Hemmer (2016), it was against this professionalized landscape in the 1940s and 50s that a group of "media activists" began to forge the modern conservative party. This first generation of media critics—such as radio host Clarence Manion and print media publishers like Henry Regnery and William Rusher-"advanced an alternative way of knowing the world, one that attacked the legitimacy of objectivity and substituted for it ideological integrity.... Media activists weren't arguing that there existed a world of objective media that they rejected and a world of ideological media they promoted. They were arguing that there was no such thing as nonideological media, that objectivity was a mask mainstream media used to hide their own ideological projects... [they advanced] a different way of weighing evidence: a different network of authorities, a different conception of fact and accuracy, and a different way of evaluating truthclaims" (Hemmer, xiii).

As a consequence of the fairness doctrine that governed radio and television, conservative activists were predominantly confined to the pages of print media. In book-long treatments and in the pages of The National Review and Human Events, conservatives contested the notion that the media offered a view from nowhere: "The concept of news itself is a source of massive confusion at the networks... management invariably pretends that 'News,' like a platonic archetype, has an immutable, independent existence and that neither human choices nor human evaluations nor human acts of selectivity or exclusion have anything to do with the phenomenon" (Efron 1971, p. 174). Efron, for example, identified and subsequently coded hundreds of hours of news coverage and used the data to ground her claims that news was constructed to fit a liberal narrative, for example, the "racist white vs. the angry black" narrative: "Network news does not report on black Americans. It reports most often on a stereotype called 'the black' ... where a complex, multiclass, morally, intellectually and politically differentiated black community should be, there is a void... the television cameras only show up when a black man steals or rapes or kills-or to film rioting, looting and violence... networks selectively tend to exclude black effort, black struggle, black courage, black resiliency, black strength, black growth, black progress, black hope, black benevolence, and above all black intelligence" (p. 144-153).

Efron was not by any means alone. Accuracy in Media was established in 1969 to ensure that conservative views received equal emphasis in news coverage and other "watchdog organizations" would follow. Television News Inc. (est. 1973) was formed as news service that would send prepared television news segments over AT\&T phone lines. As detailed by Gabriel Sherman (2014, p. 97-111), it marketed itself as news "with no philosophical axe to grind" and its founder, Robert Pauley, ostensibly aimed to produce news that was "fair and balanced." Its funding was from conservative donor Joseph Coors, it sought advice from conservative media critics, but its news room was still staffed by professional journalists who aimed for traditional notions of objectivity. One year in, Coors had seized control and fired most of the professional journalists.

As part of the transition, the governing board hired a news director with no journalistic credentials or experience: television producer and political consultant Roger Ailes. A few months later they hired another former Nixon aide, Bruce Herschensohn, to reimagine the network. Herschensohn took seriously that the news was an act of creation, advised the network to drop the 
pretense of neutrality, outlined a number of show ideas, and turned the critiques of conservative media activists into a positive playbook that could be used to "manipulate" the network's viewers. For example, by using "pretense balancing" the network would make it appear that "the presentation is showing 'all sides' of a particular story when, in fact, the balance is tilted" (Herschnsohn, as quoted by Gabriel 2014, p. 105).

Such groups were the vanguard of a new conservative movement that ultimately led to the Reagan Revolution. As noted by Hemmer (2016), a consequence of it emerging from media activists is that it became a core tenet of conservatism that the media has a liberal bias. Nevertheless, there were three camps within media activists: (1) Those who believed that any news was biased and argued for equal representation on mainstream media (e.g., Rusher 1988, p. 184); (2) those who agreed that any news was biased, but believed that such institutions were irremediably liberal and so advocated for an independent station to serve as conservative counterweight (e.g., Efron 1971, p. 215); and (3) those who believed that their own ideological frame was essentially correct, that the liberal worldview had thoroughly corrupted mainstream journalism and thus considered "the media to be part of the enemy that has to be defeated and overcome" (Limbaugh, as quoted by Jamieson \& Capella 2008, p. 72).

As long as the fairness doctrine remained in force, only the first avenue remained open and indeed conservatives in the first camp endorsed the doctrine. Thus, it was consequential when Reagan's FCC dismantled the Fairness doctrine in 1987 and when Reagan vetoed a bipartisan bill reaffirming the doctrine in 1989. The combination of the repeal with technological advancementssuch as nationwide toll-free numbers-facilitated the rise of ideologically-driven conservative talk radio hosts in the late 80s and 90s (e.g., Rush Limbaugh, Mark Levine, Sean Hannity, etc. (Hemmer 2016, p. 261)).

During the 1990s, Limbaugh's audience was more likely to listen to mainstream media than non-listeners; however Limbaugh-and subsequently other conservative news sourcesadded "a dimension missing in other media by regularly engaging in metacommunication about the frames of the mainstream (Jamieson \& Capella 2008, p. 152). Nevertheless, Jamieson and Capella (2008) found that among Limbaugh's listeners, greater exposure to mainstream media was associated with fewer distorted beliefs. However, with the introduction of Fox News to most media markets in the early aughts, such viewing decreased and the conservative media ecosystem crystallized into "a self-protective enclave hospitable to conservative beliefs" (Jamieson \& Cappella, $\mathrm{x}$ ).

This dynamic only continued to increase with the rise of internet media. Recent studies by Benkler, Fair, and Roberts (2018) have shown that conservative media online is skewed to the extreme right, insular, and disconnected from media that are committed to journalistic truthseeking norms. To be clear, there is a demand for ideologically-driven news on the left; however, the far left is integrated into a media ecosystem with mainstream news outlets. The latter "serve as a consistent check on dissemination and validation of the most extreme stories when they do

\footnotetext{
4 Though Television New Inc. would be short lived, Herschnsohn's playbook would eventually be enacted and expanded upon two decades later when Ailes became CEO of Fox News.
} 
emerge on the left, and [which] have no parallels in the level of visibility or trust that can perform the same function on the right" (p. 15). In contrast, conservative organizations that claim to follow journalistic norms (e.g., Fox News) tended to amplify and validate stories that emerged from fringe sites (e.g., Breitbart, Infowars, etc.).

Importantly, it is this media ecosystem that has brought us to the post-truth era. As I see it, what it amounts to is this: The shared space of public knowledge has deteriorated and the transpolitical institutions that had been relied on to referee political discourse no longer are recognized as legitimate by both parties. A new parallel set of ideologically-driven institutions have been created by conservatives that are themselves not recognized as legitimate or equivalent by the left. Without a shared set of standards to adjudicate disagreement, politics threatens to become the sheer exercise of power.

In place of a commitment to fact-based, objective, inquisitorial ideals of traditional journalism, conservative media operates with a value-centered (i.e., ideologically driven), constructivist, adversarial approach to reporting. To be clear, I agree with Sismondo (2017b) and Hoffman (2018) in their view that STS is not responsible for the post-truth era. As detailed above, its intellectual roots go back much too far for that. But Sismondo (2017a) misses the mark when he asserts "STS's detailed accounts of the construction of knowledge show that it requires infrastructure, effort, ingenuity and validation structures. Our arguments that it could be otherwise' (e.g. Woolgar and Lezaun 2013) are very rarely that 'it could easily be otherwise'; instead, they point to other possible infrastructures, efforts, ingenuity and validation structures. That doesn't look at all like post-truth" (p. 3).

What I hope to have illustrated above is that the analogue to STS scholarship is not Pizzagate, but the 80-year history of media activists that invested a significant amount of effort and ingenuity in building up alternative validation structures. Sismondo is correct that it is not easily otherwise. The construction of current media infrastructure was a multigenerational effort by immensely wealthy and ultimately powerful individuals and there were still many failures along the way. What the media critics share with STS scholars is that they focused on experts and institutions that claimed to be neutral and objective arbiters of the truth and, through close analysis, built up a body of evidence that knowledge was constructed and that social factors played an influential role in the process of construction.

Where they differ most significantly is that media activists and those with whom they were politically aligned took their critique of existing institutions and used it to help create a competing set of validation structures. As Hoffman (2018) notes, "the best empirical research in STS evinces a deep agnosticism about the truth" (p. 447). The reason why post-truth politics rightly caused a crisis in STS is that the conservative media ecosystem is a validation structure that is built with a similar agnosticism about objectivity and "the truth," and that validation system facilitated the rise of Donald Trump. 


\section{The Rediscovery of Bullshit}

Donald Trump is full of shit. Establishing this simple fact is sufficient to refute Fuller. The felt need to be able to do so drives the tension at the heart of this moment of self-reflection within STS. Sismondo (2017) supposes that the "post-truth era is one in which bullshit is highly valued," though I think it might be clearer to describe it as one in which bullshit is highly effective (c.f. Frankfurt 2016; Davis 2017; d'Ancona 2017; Ball 2017). Again, it is instructive to return to the distinction between lies and bullshit. The liar caught in a lie has been unmasked because the liar acknowledges a fact-based reality as a common arbiter and seeks to convince their audience of something they know to be untrue. The bullshitter simply has no care for the truth of their statements and so chooses them to the extent they serve their purpose (Frankfurt 1986). What shocked the political left was not just the detachment of Trump's rhetoric from reality, but that his complete disregard for being caught in outright lies did not disqualify his candidacy. Indeed, in Orwellian fashion, it won him a reputation for "telling it like it is."

The question that faces the STS community is whether to acknowledge such rhetorical strategies as epistemically suspect. Notoriously, Frankfurt closes his essay with a direct attack on STS doctrines:

The contemporary proliferation of bullshit also has deeper sources, in various forms of skepticism which deny that we can have any reliable access to an objective reality and which therefore reject the possibility of knowing how things truly are. These "anti-realist" doctrines undermine confidence in the value of disinterested efforts to determine what is true and what is false, and even in the intelligibility of the notion of objective inquiry. (p. 100)

While I do not find there to be a direct intellectual influence between STS and conservative media critics, I take it as given that the ability of post-truth politics to proliferate depends on an abandonment of transpolitical institutions governed by the norms of truth-seeking and objectivity. Donald Trump did not usher in an era of post-truth; he was able to thrive because the Republican media ecosystem had already brought us there. Of course, some will not be bothered (Sarewitz 2000; Fuller 2016b). However, others may now be experiencing seller's remorse and "start reassembling some of the structures we had earlier pulled apart" (Briggle 2016).

My aim is not to convince those who are inclined to maintain course that change is needed; rather, in what follows, I chart out an alternative for those who are already inclined to seek a new direction. I contend that the lesson that post-truth politics has to offer STS is that a minimal standard of an epistemological system is that it must have the intellectual resources to endorse the claim "Trump is full of shit." Minimally, we want an epistemic system in which anyone who acts like Trump (i.e. someone who repeatedly demonstrates, either through incompetence or malice, no regard for the truth) is excluded as a source of information in forming epistemic judgments. Let's call this "The Trump exclusion principle." 


\section{Thinning the Herd}

Given that one accepts the Trump exclusion principle as a minimal standard for an acceptable epistemology, STS is going to have to slaughter some sacred cows. To wit, Barnes and Bloor (1982) held that "all beliefs are on par with one another with respect to their credibility" (p. 23). Similarly, Collins (1981) asserts that "the natural world in no way constrains what is to be believed" (p. 54). Latour (1987) held that nature is determined by the settling of controversies and so whether Trump is full of shit awaits the resolution of the political dispute; if his support continues to hold we might come to learn that "Trump tells it like it is." None of these will do.

One option is simply to adopt the methods of Harry Frankfurt and analytic philosophers of science. Doing so would certainly satisfy the Trump exclusion principle because philosophers of science retain a commitment to epistemological systems with enough resources to make normative claims. However, while this would solve one problem, it would do so at the cost of losing what is distinctive and valuable about STS. Thus, in this section I want to create anvil upon which to strike the hammer created in the previous section: a set of positive criteria that current STS methods satisfy. The goal is to find an epistemology that will satisfy the Trump exclusion principle, while saving as much as possible of what is prized in STS.

Rather than generate my own list of what components of STS scholarship I have found beneficial, I will rely on Steve Woolgar's (2017) list of key STS sensibilities. This list is especially pertinent, because the list grounds Woolgar's claim that STS should stay the course despite the rise of post-truth politics. Namely, they are:

(1) STS includes "a careful working through of detailed examples."

(2) STS "avoid[s] easy categorizations and quick generalizations."

(3) STS "avoids clumping: disaggregate, disaggregate!"

(4) STS "maintains analytic skepticism"

(5) STS's "key methodological principles [are] symmetry and impartiality (e.g. between knowledge and ignorance)."

I don't think that this list is reconcilable with identifying and excluding bullshit. Again, those for whom these sensibilities are sacrosanct, I bid thee well. For the rest, it might be worth considering how little one needs to give up. In fact, in the remainder of this section I will argue that only two small changes are needed and argue that not much is lost in making them. In the next section, I will provide an outline of an alternative epistemology that STS could adopt (and develop further) and in the ensuing section I will apply that epistemology to a case study to show that it satisfies both the Trump exclusion principle and the modified list of key STS sensibilities.

I suggest that all that is needed is change one word in (4) and one word in (5), specifically:

- (4a) STS begins with analytic skepticism

- (5a) STS's key methodological principles are equity and impartiality (e.g. between knowledge and ignorance). 
These conditions can be met if we engage in something close to what Gadamer referred to as the hermeneutic circle. We begin with some so-called fact. We next engage in a process of investigation during which time certain claims are considered as uncertain and the grounds for them are investigated. After a time we crystalize our understanding of the ground and update our understanding of the whole. Of course, we can reenter the circle exploring other details, perhaps even the grounds of the claims just investigated and crystalized, and then again emerge with a subsequent understanding. Skepticism, symmetry, and impartiality have their place; they are states that we temporarily occupy, but not where we end up. At the end of the analysis we can still issue a judgment.

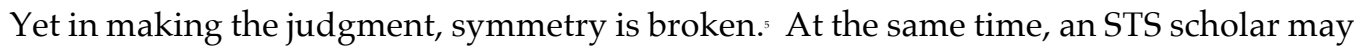
still endorse a closely related principle that I will call the equity thesis. The equity thesis: In all cases (both true and false belief), both social and non-social factors play a role in determining why some theory is pursued or some belief is provisionally accepted as truth; however, we shall give each belief only the credibility it is due. Finding social factors that incline towards belief do not preclude non-social factors from being operative, nor vice-versa.

In assessing whether trading in symmetry for equity is worth gaining the ability to satisfy the Trump exclusion principle, it is worth revisiting the founding documents of science studies as a reminder of why scholars adopted certain practices to begin with. In short, I invite STSers to momentarily employ a bit of analytical skepticism with regard to the symmetry principle.

First, recall that Barnes and Bloor (1982) were reacting primarily to a tradition in philosophy of science (especially Lakatos) that studied science as follows: To begin, one articulates a philosophical theory of how science functions, then one "rationally reconstructs" a particular episode of the history of science such that it unfolds how your theory of science claims scientists should act (irrespective of what actually happened). Finally, where the history has been distorted you add footnotes to indicate that the actual history of science unfolded differently. The best account of science is the one that casts the most rational light on science (i.e. an account that has the fewest footnotes).

To my knowledge no practicing philosopher currently takes such an approach to studying science and so insofar as Barnes and Bloor were objecting to the practice of crediting rationality with the apparent successes of science and blaming social forces for its failures, they have carried the day. But note, too, that one need not confuse a methodological assumption with an ontological commitment. Just as an economist may assume that people are rational in her analysis, but freely concede that rationality is only a useful simplifying assumption, an STS scholar may adopt symmetry as a methodological assumption. It may well be a useful stricture to correct for overconfidence in the epistemic justification of current knowledge, but scholars need not forget it is only a methodological stricture. As Barnes and Bloor (1982, p. 47) emphasize, "if relativism has appeal at all, it will be to those who wish to engage in that eccentric activity called 'disinterested research."'

\footnotetext{
${ }^{5}$ At least in so far as "symmetry" means explaining all beliefs with social causes. If symmetry only means that the same types of causes are used to explain both true and false beliefs then symmetry is maintained.
} 
Adopting symmetry as a methodological principle is echoed by both Collins (1981) and Latour and Woolgar (1979/1986). In the full text of his infamous quote, Collins makes clear it is a first and foremost a methodological recommendation: "The appropriate attitude for conducting this kind of inquiry is to assume that 'the natural world in no way constrains what is believed to be"' (p. 54, emphasis added). Likewise, while Latour and Woolgar claim that "scientific achievements held to be correct should be just as amenable to sociological analysis as those thought to be wrong," they adopt it as a means of "resisting the temptation to go native, we shall attempt to explain [scientists'] use of these concepts as a social phenomenon (p. 39)." In later work, Latour (1987, p. 247) expresses a similar type of methodological justification for first attempting to appeal to the social: "first look at how the observer moves in space and time, how the mobility, stability and combinability of inscriptions are enhanced, how the networks are extended, how all the informations [sic] are tied together in re-representation, and if, by some extraordinary chance there is something unaccounted for, then and only then look for special cognitive abilities." But of course there is something left out of such accounts and that is how the world pushes back on our investigations-a world that makes our statements true or false and determines whether empirical endeavors fail or succeed.

In short, what one gives up in trading in symmetry for equity is not something STS discovered about the world, but rather a methodological assumption that is intended to facilitate a certain type of inquiry. Methodological assumptions are justified on pragmatic grounds, whether or not they serve our epistemic goals. What I will argue below is that adopting the equity thesis retains nearly all of the methodological virtues of symmetry and provides the normative bite needed to call out bullshit.

\section{It Should Be Otherwise}

The reason I am confident that only minimal changes are needed is that philosophers of science have already wrestled with these challenges and produced alternatives. Though a majority of philosophers of science resisted or dismissed developments in STS (e.g., Sokal \& Bricmont 1999), a minority of philosophers took a more charitable stance. These philosophers accepted the primary critique that scientific knowledge could not be separated from the context of its production; however, they sought to preserve the traditional philosophical commitment to some normative virtue (e.g. objectivity, truth, rationality). The result was the rise of social epistemology(ps).r I suggest that such work, already informed by STS roots, can, in turn, again cross the disciplinary divide and serve as intellectual catalyst for STS. Even should these frameworks be judged unsatisfactory, they provide a good starting point for future work.

\footnotetext{
${ }^{6}$ Treating objects as having agency already gives up the game and reintroduces the world as an arbiter of inquiry under the guise of social phenomena, but is a misleading and obscure way of speaking.

${ }^{7}$ I deal here with social epistemology as it has been developed in philosophy of science. Because that term refers to a different set of views in STS, I will add a "(ps)" to remind the reader.
} 
As I see it, the primary tension in the science war is fundamentally this: how do we explain why science is epistemically superior to other systems of belief generation while acknowledging that science is, as was so eloquently put by Steve Shapin, "produced by people with bodies, situated in time, space, culture, and society, struggling for credibility and authority." From the purview of STS, philosophy of science appeared sterile, disconnected from and unrelated to, what scientists do in the lab. When empirical studies focus in on the activities of the individual scientists, the image of a noble dispassionate seeker of truth resolves into a human being with the same sort of ego, social prejudices, and psychological frailties as the rest of us. This seemed to make philosophy of science about some mythical activity engaged in by no one, ever.

However, what is also undeniably true, is that science is the only social institution that flung a group of primates to the moon and brought them back, eradicated diseases that used to be the scourges of humanity, and continues to achieve feats that, to uninitiated, are often indistinguishable from stage magic. This type of achievement makes any suggestion that science is "just another way of knowing" untenable. The interesting question is how the scientific enterprise has achieved such remarkable success despite the fact that it is conducted by such a flawed bunch of creatures.

The unifying feature of the social epistemology(ps) of Helen Longino (2002), Alvin Goldman (1999), and Miriam Solomon (2001) is that they hold that virtues of science arise from its social structure rather than the inherent goodness of its practitioners. Informed by the work in science studies (e.g. Barnes, Bloor, Latour, Knorr-Cetina), they grant that science is a social activity in which not only do scientists inherit methods, concepts, and standards from a community, but in which the very processes that are responsible for the production of scientific knowledge are social processes.

As an example, consider the work of Helen Longino (1990; 2002). Her critical contextual empiricism aims at tearing down the false dichotomy between a theory that is rationally justified and a theory that was accepted because of social influence. Positively she aims to produce "an account of scientific knowledge that is responsive to the normative uses of 'knowledge' and to the social conditions in which science is produced" (Longino 2002, p.1, italics in original). Again, drawing from the insights of social studies of science, her account allows that basic scientific activities (e.g. observation and reasoning) are themselves social practices engaged in by interdependent individuals. Her focus is precisely on these negotiations within a community and the circumstances under which the deliverances of such activities should be counted as knowledge.

In the background of Longino's (1990) account is the claim that the incorporation of feminist values into inquiry produced epistemically superior science. Thus, "good science" does not equate with "ideologically neutral." What Longino takes to have been missing was effective critical discourse that is able to "transform the subjective into the objective, not by canonizing one subjectivity over others, but by assuring that what is ratified as knowledge has survived criticism from multiple different points of view" (2002, p. 129). Meeting such a standard requires: (a) that there are venues for critical discourse to discuss methods, findings, assumptions, and evidential standards; (b) that there is uptake of criticism by the community when it is warranted; (c) that there are commonly agreed upon goals and publicly available standards of evaluation, such that debate 
can be adjudicated in a non-capricious manner; and (d) that the distribution of authority in the community respects the condition of tempered equality. Of course, this is only a small window into her philosophy, but in the next two sections I will show that it provides the epistemic tools needed to supplement other modes of STS interrogation.

\section{Sex, Drugs, and Money}

An example of a claim that might be subject to STS interrogation is: "The drug Addyi (flibanserin) treats hypoactive sexual desire disorder in premenopausal women." For example, one might interrogate the medicalization of women's sexuality that leads to low levels of desire being classified as pathological, indeed the very conception of "normal sexuality" to which "low levels" implicitly refers. The boundaries of each of the terms all have rich histories that could be and have been explored (e.g. Fishman 2004; Moynihan \& Mintzes 2010). The thread I want to pull on here is the term "treats," not generally (though that would be fascinating, too), but in this specific case.s Even if we accept these terms at face value, what justifies the claim that flibanserin is an effective treatment?

At least in the United States, this claim has been certified by the FDA since August of 2015; however, prior to this, the drug had been rejected twice before. In both previous applications the FDA concluded that it had not been shown that benefits of flibanserin outweighed its likely harms. Even on the third attempt to gain approval, the medical reviewers, statistical reviewers, clinical pharmacology reviewers, and the team-leader in charge of the application all concluded that there was an overall negative risk/ benefit balance and recommended against approving flibanserin. In contrast, a group of independent experts charged with advising the FDA disagreed. In his approval letter, the division director noted that there was "internal agreement of the facts, but not on whether the demonstrated benefits outweighed the known risks" (FDA 2015b, p.23). Little new information was presented along with the third and successful approval; instead, what changed was the evaluation of the balance of benefits and harms. A primary input to this change was a meeting convened by the FDA to ensure its decisions stay in touch with patient needs, in particular the extent to which patients experience the therapeutic effects as meaningful and the side-effects as debilitating.

As conveyed in the briefing document to the expert advisory committee, women diagnosed with hypoactive sexual desire disorder exhibited "a willingness to risk serious (and often unknown) adverse effects and even to undergo periodic minor surgery with its related risk of serious infection in order to obtain [FSD] relief" (FDA 2015a, p.xvi). Indeed, many of the women at the meeting had participated in the drug trial and they reported that "the effects of flibanserin [are] clinically meaningful and important to their condition" (p. 92). Thus, it seems we have a case

\footnotetext{
${ }^{8}$ As this paper is a meta-reflection on knowledge production, in what follows I consider fictionalized account of analyzing a fact, modeled on Latour's (1987) "dissenter." Except for a few minor reversals in the chronology of investigation, it reports the process a colleague and I did go through in our analysis. In actual fact we moved from the approval letter to the patient meeting and then examined how the effects of the patient meeting was filtered through official documents.
} 
where the patient meeting functioned precisely as it was supposed to. Bureaucrats had paternalistically kept a drug off the market because they failed to realize how important and meaningful even small improvements could be for women. Putting decision makers in touch with the lived experience of women suffering from hypoactive sexual desire disorder sensitized officials to the fact that their estimation of the balance of risks and benefits was out of step with the women they were ostensibly serving.

However, in line the key virtues of STS, I began the investigation with analytic skepticism as to whether that is true. Next, I began to consider the grounds for the FDA's claim about women's experience. To do so I took the transcripts of that day and used grounded theory analysis to discern the meaning expressed in the patient discussion. It turned out that many of the women in attendance had been brought into the meeting as part of a public relations campaign by Sprout Pharmaceuticals. To ensure my analysis was not biased by this knowledge, I removed all disclosure of conflicts of interest and had a colleague unfamiliar with any of the details of the case repeat the analysis. Without any context for the meeting, she arrived at the same result: Women had fundamentally different experiences of sexual dysfunction depending on whether they understood it to be a biological dysfunction. After her analysis was complete, I unblinded my colleague and she learned that all of the women who viewed their sexual dysfunction as a biological dysfunction had been brought to the meeting by Sprout pharmaceuticals, the manufacturer of Addyi (for further methodological details see: Holman \& Geislar, 2018).

To be clear, we also found a wide swath of agreement in the underlying phenomena. All women reported that they experienced a lack of sexual desire and that this could cause problems in areas far removed from their sex lives. For example, $\mathrm{Meg}^{*}$ relayed how such issues affected her at work. "I mean that affects all areas of my life including-at work how well I can perform. I get brain fog. I start crying, which I never cry at work. I mean because I have 50 employees and you know you can't cry in front of 50 employees.", Similarly, Kelly noted that "It doesn't just affect the female. It affects the male and their mental state which affects your relationship which affects how you deal with the kids and with everybody else and how you think of yourself." In order to ease some of the strain in their relationship women engaged in sex out of an obligation: "Essentially it starts out being duty sex and if you are lucky it turns into great sex" (Sue*).

Despite this shared set of experiences, we found that they were organized and interpreted in two dramatically different ways. Moreover, these differences were completely explained by whether women had their travel and lodging organized and paid for by Sprout Pharmaceuticals. Such women, like Carmon*, understood their lack of sexual desire as a biological disorder: "Yeah, I was a busy mom and needed to get more sleep. But the problem was actually physical with me. It wasn't a mental problem." Understanding the problem as biological was also associated with a rejection of the change. Women sought to reclaim a previous level of sexual desire. For example, as Katherine* put it: "I feel like my body has let me down... I feel I pulled a bait and switch on my

\footnotetext{
${ }^{9}$ In what follows we distinguish women who were brought to the meeting by Sprout Pharmaceuticals from those who were not by placing an asterisk after the names of the former. All participant quotations come from the transcript of the day's events (FDA 2014).
} 
husband who is undoubtedly wondering where the old me has run off to." Feeling as if their body had betrayed them was another sentiment repeatedly expressed by women who understood their problem as physical. Finally, they critiqued the FDA for holding back a drug for female sexual dysfunction when it had already approved so many for men.

In contrast to women brought in by the pharmaceutical company, women whose travel was not industry-sponsored understood their lack of desire as primarily an outcome of problems in their relationship: "We learned... that our sexual problems were a co-created problem in our relationship and that I wasn't the problem... [this] helped changed our thinking from pathological to relational" (Susan). Corresponding to this understanding was an acceptance that sexuality would change over the course of a relationship and with aging: "For my part I accept the reality of my age and past challenges. I do not hold an unrealistic expectation associated with the cultural pressures to be forever young, beautiful and sexy. I, and many other women, young or old are not ever going to achieve the mind blowing nirvana of orgasmic ecstasy that saturates our popular culture" (Karen). Embedded in sentiments like this was a different type of feminist critique, one that challenged societal expectations of women's sexuality and the way that these structured women's expectations of themselves. Susan found that it was these "culturally driven definitions of normal that creates distress and anxiety." Similarly, Thea felt embarrassed about how long it took her to have an orgasm, "because in porn, in culture, in Hollywood movies it seemed very easy for women. So there was a lot of shame in that." This critique challenges the basic assumptions underlying the medicalization of women's sexuality. ${ }^{10}$

More detail would be needed to make the case fully (see Holman \& Geislar, 2018), but given that the full analysis bears out this description, we have reached a sort of terminus. We began with a particular fact and dug down until we got to the point where we found how this supposedly neutral fact arose from social power. Specifically, we have shown that the FDA's revaluation of the risks and benefits of flibanserin were the direct result of Sprout Pharmaceuticals' ability to bring to the FDA women who would report experiences that would support approval. So successful was this effort that roughly two-thirds of the women who spoke at the day-long meeting were associated with the company. Perhaps because of this predominance, when the FDA summarized the event for the independent advisory committee, the experience of women not associated with Sprout Pharmaceuticals was completely drowned out.

We have now established a perfectly good STS conclusion: it could have been otherwise. However, to pull out of our skeptical attitude and issue a judgment regarding which of these two possible conclusions should be endorsed given our new understanding, we need more tools than

\footnotetext{
${ }^{10}$ This challenge did not go unnoticed. Despite being asked by the FDA to "stay in listening mode" so that patients' voices could be heard, at one point a researcher broke form and interjected "with all due respect to the normalcy of desire... I think the premise of this whole meeting is about an unmet medical need and that we're all agreed that this is a condition that we are working to find treatments for." The researcher provided her academic credentials, but did not disclose her ties to Sprout Pharmaceuticals.
} 
STS provides. Here, Longino's framework is especially well-suited to analyze what went wrong in the flibanserin case.

First, it should be noted that the FDA did many things well. The institution of the patient drug development meeting created a venue for critical discourse. They also took care to solicit views beforehand so that they could begin each session with a diversity of views. However, as work by Segal (2018) has shown, the presence of industry-sponsored women was part of a much larger public relations effort by Sprout Pharmaceuticals to get Flibanserin approved, adopting a faux feminism that was clearly bullshit.

Specifically, the "Even the Score" campaign alleged that the fact that the FDA had witheld approval from previous treatments for female sexual dysfunction indicated sexism. They claimed that men had 26 treatments to treat sexual dysfunction, but women had none. Yet these "26 treatments" were actually five different products sold under different names, all aimed at inducing an erection. In fact, no treatment had been approved for low sexual desire in either men or women prior to Flibanserin. In addition, the campaign cited discredited research, and relied on researchers who have repeatedly claimed that low sexual desire is a biological problem in support of numerous drugs that have fundamentally distinct mechanisms of action.

As shown by Segal, the bullshit put out by the campaign was brought into the patient development meeting through the mouths of the patients in a process of corporate ventriloquism. Other women who came to the patient drug development meeting challenged the assumptions underlying the medicalization of women's sexual lives, however, the FDA failed to have any mechanisms for uptake of criticism (Beuter \& Jukola, 2020). More crucially, what seems transparently clear is that by allowing Sprout Pharmaceuticals to stack the meeting with friendly testimony, the FDA failed to satisfy a condition of tempered equality. Thus, Longino gives us grounds to say not only could it have been otherwise, but that it should have been.

\section{We Ought Not to Despair of Better}

In closing, I want to reassure you that I've made good on my promises. So first, with respect to the Trump exclusion principle, consider what happens to a bullshitter inside the ideal community. Here it is important to consider the 2002 version of Longino's account, which added "tempered" to the "equality of authority" condition. This addition addresses concerns that mere equality would cede credit to community members that continued to advocate positions despite cogent critiques of their arguments. Such a condition either denies a bullshitter further legitimacy in the discourse or forces them to conform to the norms of the community whereupon they are no longer full of shit.

On the other side of the coin, I hope that it becomes apparent that while philosophy of science typically does not include a careful working through of detailed examples, an interrogation of categorizations and generalizations, and a disaggregation of what science has put together (i.e. Woolgar's criteria 1-3), such work can be carried out under a variety of epistemological frameworks. After working through the above example we ended up with a disaggregation of women's experience formally categorized under a single banner. 
With respect to criteria (4a) and (5a), note that we began the process with an analytical skepticism, prodding and poking the series of justifications given for the so-called facts and finding that some of them held up to scrutiny and others did not. After completing these diagnostics, we employed Longino's framework to conclude that some beliefs were due more credibility than others. While this is a break of symmetry, it is fully in keeping with a principle of equity.

Finally, one might object that in breaking symmetry and endorsing one view over another we have violated impartiality. This however is mistaken. An impartial judge does not forever withhold a verdict, she merely begins the trial with an open mind and applies the rules justly to both sides; having done so she is able to render an impartial verdict.

Thus, the deal on the table for STS scholars is to abandon symmetry in return for equity and the ability to aver that Trump is full of shit. To be clear, this is to sign on to a project rather than to accept a view lock, stock, and barrel. As I have argued elsewhere (Holman, 2019), I do not believe that Longino's account or any of the other social epistemological(ps) frameworks are completely satisfactory; however, I do think they offer some useful signposts for moving forward. I also feel that practically oriented philosophers of science would benefit again from interacting with science studies scholars (I certainly have).

In closing, there is one further reason to help develop such accounts, which is frankly the most important: There is a pressing need to cultivate good epistemic practices that have public legitimacy. It is more than an academic dispute. This is a social issue that society is grappling with now and that STS is well-suited to address. We, all of us, need help and to help. Of course, that presumes (as I have) that the reader sees the issues as in need of being addressed. Assuming so, I have laid out some intellectual terrain that might help people find their footing.

As for the vestiges of the science wars, perhaps those who have been marching under the banner of "Anything goes" and "It could have been otherwise" may now be in a position to consider the great conservative wisdom put forward by Edmund Burke in the wake of the horrors of the French revolution. There is a value and a virtue to order and rules and so a citizen's inclinations may be, in fact often should be, thwarted, controlled, and brought into control by a transpolitical actor. Our institutions, be they epistemic or political, properly arranged, can stop governance from being merely the will of the strong and "in this sense, the restraints on men [sic] as well as their liberties are to be reckoned among their rights" (Burke 1790/1834, p. 404).

\section{Author Biography}

Bennett Holman (PhD UC Irvine) is an Assistant Professor of the History and Philosophy of Science at Yonsei University in Seoul, South Korea, and a senior research associate at the University of Johannesburg. His research is primarily focused on improving scientific epistemology in areas of science heavily influenced by industry funding, especially pharmaceutical research. He has additional interests in political polarization and epistemological systems within a politically fractured polity. 


\section{Acknowledgements}

A most sincere gratitude is owed to Managing Editor Katie Vann. This paper was first drafted in October of 2017, has been through innumerable revisions, and was occasionally left for dead. It would never have been published without her patience, kindness, and support. I would also like to thank Kean Birch, Johan Söderberg, and the anonymous referees who all pushed me to clarify my thoughts and substantiate my claims where I would have rather engaged in a bit of hand waving. The paper is truly much better for it and certainly contains less bullshit. The paper was also improved by comments from Heather Douglas, Greg Lusk, Kevin Elliott, Chris ChoGlueck, Adrian Erasmus, Tim Fuller, and the attendees of the Lyman Briggs Sociology of Science Works in Progress seminar. A thanks is also due to the scholars of conservative media who gave of their time and helped me improve my understanding of their work, including Nicole Hemmer, Tom Medvetz, and Matt Grossman. As ever, I bear full responsibility for any remaining inaccuracies. A final acknowledgement is due to Vox reporter David Roberts whose writing on tribal epistemology and the conservative media have shaped my thinking in ways I am not sufficiently able to capture.

\section{References}

d'Ancona, M. 2017. Post-truth: The New War on Truth and How to Fight Back. London: Ebury Press. Ball, J. 2017. Post-truth: How Bullshit Conquered the World. London: Biteback Publishing.

Barnes, B., and D. Bloor. 1982 "Relativism, rationalism and the sociology of knowledge." In Rationality and Relativism. edited by M. Hollis and S. Lukes, England Basil Blackwell, 21-47. Cambridge MA: MIT Press.

Benkler, Y., R. Faris, R., and H. Roberts, H. (2018). Network propaganda: Manipulation, disinformation, and radicalization in American politics. Oxford University Press.

Beuter, A., and Jukola, S. (2020). Sex Drugs and How to deal with Criticism-The Case of Flibanserin. In B. Osimani and A. La Caze (Eds.) Uncertainty in Pharmacology: Epistemology, Methods and Decisions. Boston: Springer.

Briggle, A. 2016. "Post-Truth Blues?" Social Epistemology Review and Reply Collective. Accessed 13 October 2017: https://social-epistemology.com/2016/12/22/post-truth-blues-adam briggle/

Burke, E. 1790/1834. The Works of the Right Hon. Edmund Burke: With a Biographical and Critical Introduction. London: Holdsworth and Ball.

Collins, Harry M. 1981. "Son of seven sexes: The social destruction of a physical phenomenon." Social Studies of Science 11: 33-62.

Davis, E. 2017. Post-truth: Why We Have Reached Peak Bullshit and What We Can Do About It. New York, NY: Little Brown Book Group.

Efron, E. (1971). The news twisters. Nash Publishers

FDA 2014. "Female Sexual Dysfunction Patient -Focused Drug Development Public Meeting." US Food and Drug Administration, Washington, DC. 
FDA 2015a. "Flibanserin for the Treatment of Hypoactive Sexual Desire Disorder in Premenopausal Women." NDA 022526 advisory committee briefing document. 4 June, 2015.

FDA 2015b. “Division Director Review NDA 022526." Reference ID 3808082.

Fernandez Pinto, M. 2017. “To Know or Better Not To." Science \& Technology Studies 30: 53-72.

Fishman, J. 2004. "Manufacturing Desire: The Commodification of Female Sexual Dysfunction." Social Studies of Science 34: 187-218.

Frankfurt, H. G. 1986. “On Bullshit.” Raritan 6: 81-100.

Frankfurt, H. G. 2016. “Donald Trump Is BS, Says Expert in BS.” Accessed 13 October 2017 http://time.com/4321036/donald-trump-bs/

Fuller, S. 2016a. "Science Has Always Been a Bit 'Post-truth." The Guardian, Accessed 13 October 2017: https:/ / www.theguardian.com/science/political-science/2016/dec/15/ science has-always-been-a-bit-post-truth

Fuller, S. 2016b. "Embrace the Inner Fox: Post-truth as the STS Symmetry Principle Universalized." Social Epistemology Review and Reply Collective, Accessed 13 October 2017: https: / / social-epistemology.com/2016/12 / 25/embrace-the-inner-fox-post-truth-as-the sts-symmetry-principle-universalized-steve-fuller /

Goldman, A. 1999. Knowledge in a Social World. New York, NY: Oxford University Press.

Hemmer, N. (2016). Messengers of the right: Conservative media and the transformation of American politics. University of Pennsylvania Press.

Hoffman, S. G. (2018). The Responsibilities and Obligations of STS in a Moment of Post-Truth Demagoguery. Engaging Science, Technology, and Society, 4, 444-452.

Holman, B. (2019). Philosophers on Drugs. Synthese, 196, 4363-4390.

Holman, B. and Geislar, S. (2018). Sex Drugs and Corporate Ventriloquism: How to Evaluate Science Policies Intended to Manage Industry Bias, Philosophy of Science, 85, 869-881.

Jamieson, K. H., and Cappella, J. N. (2008). Echo chamber: Rush Limbaugh and the conservative media establishment. Oxford University Press.

Ladd, J. M. 2011. Why Americans hate the media and how it matters. Princeton, NJ: Princeton University Press, 2011.

Latour, B. 1987. Science in Action: How to Follow Scientists and Engineers Through Society. Cambridge, MA: Harvard University Press.

Latour, B. 2004. "Why has Critique Run out of Steam? From Matters of Fact to Matters of Concern." Critical Inquiry 30: 225-248.

Latour, B., and S. Woolgar. 1979/1986. Laboratory Life: The Construction of Scientific Facts. Princeton, NJ: Princeton University Press.

Limbaugh, R. 2009. Accessed 6 February 2018: https:/ / www.rushlimbaugh.com/daily/2009/11/24/climategate_hoax_the_universe_ _lies_versus_the_universe_of_reality/

Longino, H. E. 1990. Science as Social Knowledge: Values and Objectivity in Scientific Inquiry. Princeton, NJ: Princeton University Press.

Longino, H. E. 2002. The Fate of Knowledge. Princeton, NJ: Princeton University Press. 
Luntz, F. 2002. “Straight talk." Accessed 2 February 2018:

https: / / www.motherjones.com/files / LuntzResearch_environment.pdf

Michaels, D. 2008. Doubt is Their Product: How Industry's Assault on Science Threatens Your Health. New York, NY: Oxford University Press.

Mirowski, P. 2013. Never Let a Serious Crisis Go to Waste: How Neoliberalism Survived the Financial Meltdown. Brooklyn, NY: Verso Books.

Moynihan, R., and B. Mintzes. 2010. Sex, Lies and Pharmaceuticals. How Drug Companies Plan to Profit from Female Sexual Dysfunction. Vancouver, BC: Greystone.

Roberts, D. 2017. Donald Trump and the Rise of Tribal Epistemology. Accessed 6 February 2018: https: / www.vox.com/ policy-and-politics / 2017/3/22/14762030/ donald-trumptribal-epistemology

Rusher, W. A. (1988). The coming battle for the media: Curbing the power of the media elite. William Morrow \& Company.

Sarewitz, D. 2000. "Science and Environmental Policy: An Excess of Objectivity." In Earth Matters: The Earth Sciences, Philosophy, and the Claims of Community. edited by R. Frodeman, 79-98. Upper Saddle River, NJ: Prentice-Hall.

Segal, J. Z. (2018). Sex, drugs, and rhetoric: The case of flibanserin for 'female sexual dysfunction'. Social studies of science, 48(4), 459-482.

Sherman, G. (2014). The Loudest Voice in the Room: How the Brilliant, Bombastic Roger Ailes Built Fox News--and Divided a Country. Random House Incorporated.

Sismondo, S. 2017a. "Post-truth?" Social Studies of Science, 47: 3-6.

Sismondo, S. (2017). Casting a wider net: A reply to Collins, Evans and Weinel. Social studies of science, 47(4), 587-592.

Sokal, A., and J. Bricmont. 1999. Fashionable Nonsense: Postmodern Intellectuals' Abuse of Science. New York, NY: Picador Press

Solomon, M. 2001. Social Empiricism. Cambridge, MA: MIT press.

Woolgar, S. 2017. "It Could Be Otherwise in Times of Trouble." Delivered at: On the Limits of Knowing: Political Economy of Technoscience, Boston, August. 